The collections included a large series of fishes and invertebrates, which have been handed over to the Indian Museum to be worked out.

Only a short time could be devoted to the fisheries of the Sandarbans, that vast area in the Ganges delta which includes large rivers and pestiferous creeks where fish-life is impossible, but such observations as could be made indicate that here too profitable fisheries could be established, for it is to the Sandarwans that the hilsa (Indian shad), one of the most esteemed of Calcutia lood-fishes, resorts for the purpose of spawning

As a preliminary to the development of the rich fisheries of Bengal, it is recommended that a Fisheries Department should be established by the Indian Government without delay.

R. L.

\section{DISINTEGRATING BACTERIA AND OTHER ORGANIC CELLS.}

BACTERIAL toxins may be broadly divided into two varieties. In one of these the toxin is excreted into the medium on which the organisms are cultivated, and in the other type the toxin is retained within and forms an integral part of the living bacterial cell.

It is now generally recognised that the diseaseproducing effects of pathogenic micro-organisms are almost entirely due to the toxins, whether intracellular or extracellular, which they secrete. For immunising purposes or for the preparation of anti-sera, the toxin which is excreted may be obtained from the culture medium by filtration through a porous porcelain filter, such as the Pasteur-Chamberland, the organisms being retained by the filter and the toxin passing through. The diphtheria and tetanus bacillus are examples of this type.

The majority of micro-organisms, however, do not excrete licir toxin, at least to any extent, and among those that retain it within the cell are typhoid, cholera, plague, glanders, $B$. coli, B. streptococci, B. staphylococci, \&c. In these cases some method of rupturing the cell-wall, so that the contents may escape, has been found to be desirable. This allows of not only the use of the toxin as such, but also renders it possible to investigate the chemical composition and properties of the bacterial proteins and other cell constituents.

The apparatus to be described fulfils the required conditions, and causes the cell-wall to be ruptured so that the contents are obtained unaltered. It is necessary that there should be no appreciable rise of temperature during the operation, apart even from any extraneous cooling arrangement, or else chemical change would occur; the apparatus therefore must be so far as possible frictionless. Every organism must come under the grinding action, so that either no whole cells remain or their number is reduced to a minimum. The containing vessel in which the grinding action takes place must be so effectually sealed that, during the process of disintegration, no cells have any opportunity of escaping. This applies particularly when pathogenic organisms are being dealt with. The apparatus as designed is made in two forms; in one (Fig. I) it is mounted between horizontal centres, and in the other (Fig. 2) between vertical centres. In the former the grinding action is controlled by gravity, and in the latter by electromagnetic means.

The appliance consists essentially of a phosphor bronze or steel pot or vessel, $\mathrm{A}$, in which a number of steel balls, B, are allowed to revolve. The steel balls accurately fit the inside of the containing vessel, so that as the machine rotates they are in contact NO. 22 IO, VOL. 89] over nearly one-half of their circumference with the inside of the vessel. A metal cage, $\mathrm{C}$, is made of such a shape that its prongs lie between the balls, so that the latter cannot collide one with another when the machine is rotating. Mounted at the centre of the metal vessel is a steel cone, $D$, which is of such a size that it keeps the balls in their proper position in close contact with the periphery of the containing vessel. This cone is an important part of the apparatus as upon it depends the pressure that may be exerted on the balls; and, further, as the result of its use the balls themselves have freedom to slip

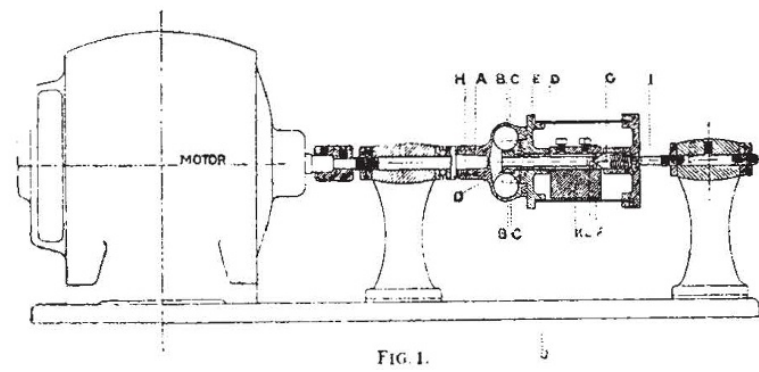

if any additional strain is thrown on them, or if any undue amount of material comes under their action. The containing vessel is closed by a metal cap, E, which screws down, hermetically sealing the vessel. A groove is made in the top of the containing vessel into which a lip on this screw cap loosely fitc. Sufficient space remains between the two, as shown in the figure, to allow of some bacterial agent being placed therein, thus effectually preventing the escape of whole bacteria or ground material from the containing vessel. Over the whole of this a cylindrical cap, $\mathrm{F}$, is placed, and in the top of this cap a metal cone, $\mathrm{G}$,

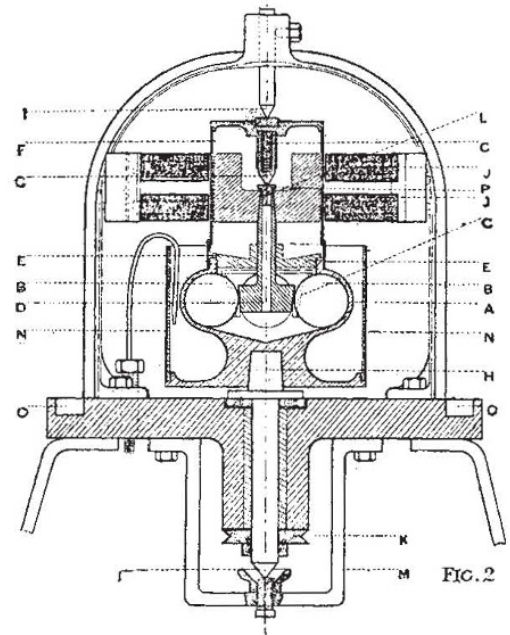

is fitted, which presses by means of a spring on to the top of the steel cone, D. The steel cone is itself hollow, and is closed by a small metal cap, L. A lead or steel weight, $K$, is fitted on to the steel spindle, D, and is clamped on any desired position along it.

The apparatus is mounted on a cone, $\mathrm{H}$, and runs between this cone and the centre, I. It may be conveniently connected directly up to a motor, as shown in the illustration, or may be driven by a belt from any suitable source of power by putting a grooved pulley on to the left-hand end of the spindle.

The grinding action takes place between the steel 
balls contained in the metal vessel and the interior surface of the same. It is evident that if the weight, $\mathrm{K}$, were not on the central cone, as shown, or unless some similar method were adopted to control the cone to prevent it from rotating, no grinding action would result; the central cone, in fact, must either remain still or be allowed to rotate at a slower speed than the containing vessel. The metal weight, $\mathrm{K}$, is of such size that on the whole machine being driven at a suitable speed the action of gravity results in the steel cone remaining still, and so a grinding action takes place between the steel balls and the inside surface of the containing vessel. To bring the bacterial or other cells under the grinding action of the balls, the speed of rotation should be from rooo to 1500 revolutions per minute; centrifugal action is then sufficient to ensure that the whole of the material does actually come between the balls and the metal vessel.

The method of using the machine is briefly as follows:- The bacteria, after being removed from the culture tubes or plates on which they are grown, are centrifugalised; the semi-fluid mass is then emulsified with saline solution, so that it is of a creamy consistence. This material is then introduced into the container by means of a pipette through the hollow centre of the steel cone. This ensures that no parts
The effect of disintegrating yeast cells for ten and fifteen minutes is seen in Figs. 4 and 5 respectively, Fig. 3 showing the cells before the commencement of the process. It is interesting to note that in Fig. 5 the cell contents have taken up the stain which was used in making the microscopical preparation, whereas the cell envelopes remain unstained and show as clear areas, thus demonstrating that the cell contents have been completely expressed. J. E. BARNARD.

\section{UNIVERSITY AND EDUCATIONAL INTELLIGENCE.}

Cambridge.-Mr. E. A. Newell Arber, of Trinity College, has been approved by the general board of studies for the degree of doctor of science.

The general board of studies has issued an important report on advanced students, of which there are at present two classes: (r) those who qualify for a degree by submitting a dissertation approved by a degree committee of a special board, and (2) those who qualify for a degree by reaching a certain specified standard in a tripos examination. The board points out that there is considerable variation in the standard required of advanced students in the various tripos examinations.

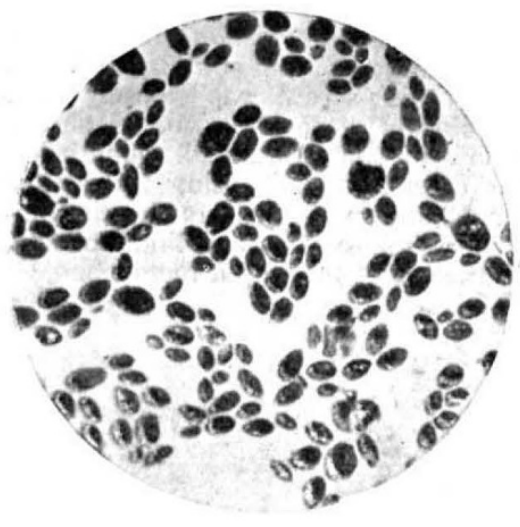

$F_{I G} ;$

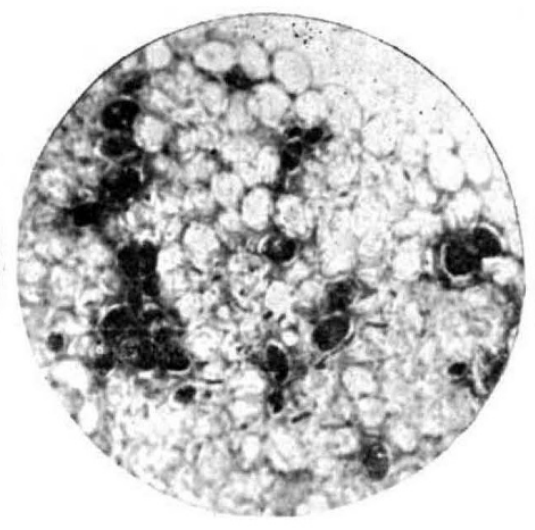

FIG, 4.

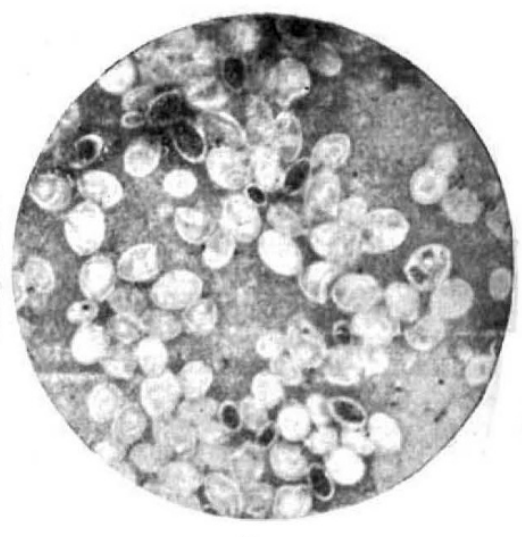

FIG. 5 . of the machine are disturbe' more than is absoluely necessary either before or after grinding. The machine is then run for a longer or shorter period, depending on the amount of material to be dealt with, and the ground material is then pipetted off through the central steel cone. As the balls are themselves free to rotate, the amount of friction is negligible, but any rise of temperature may be prevented by allowing a small stream of carbonic acid gas from a cylinder of liquid carbonic acid to impinge on to the side of the vessel; alternatively an ether spray, such as is used for section-cutting purposes, may be used, and will be found quite efficient.

The vertical type of machine (Fig. 2) is exactly similar in all essential details, except that the central steel cone is controlled by means of electromagnets. On the top of the cone a mass of soft iron is fixed, and this is kept from rotating by means of the elect:?magnets, $J$. The only constructional difference is that the containing cylinder, $F$, is made of vulcanite, so that it is perfectly diamagnetic. The chief advantage of this design over the one previously described is that it can be completely covered by a glass bell-jar while in action. A bactericidal agent may be placed in the groove $O$, and the bottom edge of a bell-jar allowed to dip into it.

NO. 22 IO, VOL. 89]
The number of advanced students of the latter class admitted to courses of study in the fourteen years from 1896 to 1909 inclusive was ror. In the same period eight applications were refused. Of the IoI admitted, 35 reached the standard required in their respective tripos examinations; I8 were rejected; 48 did not present themselves for examination. These statistics point to the conclusion that a good many students are admitted to the status of advanced students who have no real claim to the distinction which such admission may be held to confer.

After full consideration of the working of the present regulations, the general board has come to the conclusion that it is desirable that advanced students should no longer be admitted to courses of advanced study, but that they should be admitted to courses of research only.

With this end in view, the board proposes that the class of affiliated students should be enlarged, and that affiliated students should not only be permitted to proceed to a degree after residing in the University for six terms, but in the case of certain tripos examinations should be also admitted to the second part without necessarily having fulfilled the ordinary condition of having previously passed in the first part of the tripos or in some other tripos. 